\title{
THE EFFECT OF FIBER ORIENTATION AND LAMINATE STACKING SEQUENCES ON THE TORSIONAL NATURAL FREQUENCIES OF LAMINATED COMPOSITE BEAMS
}

\author{
Mohammed Fahmy Aly ${ }^{1}$, Galal.A.Hassan ${ }^{2}$, Ibrahim Goda ${ }^{3}$ \\ ${ }^{1}$ Industrial Engineering Department, Faculty of Engineering, Fayoum University, Fayoum, Egypt \\ Mfahmy_aly@yahoo.com,Mfa03@Fayoum.edu.eg \\ ${ }^{2}$ Mechanical Design and Production Department, Faculty of Engineering, Cairo University, Giza 12613, Egypt \\ Galalhassaan@ymail.com \\ ${ }^{3}$ Industrial Engineering Department, Faculty of Engineering, Fayoum University, Fayoum, Egypt \\ igm00@fayoum.edu.eg
}

\begin{abstract}
The composite materials are well known by their excellent combination of high structural stiffness and low weight. The main feature of these anisotropic materials is their ability to be tailored for specific applications by optimizing design parameters such as stacking sequence, ply orientation and performance targets. Finding free torsional vibrations characteristics of laminated composite beams is one of the bases for designing and modeling of industrial products. With these requirements, this work considers the free torsional vibrations for laminated composite beams of doubly symmetrical cross sections. The torsional vibrations of the laminated beams are analyzed analytically based on the classical lamination theory, and accounts for the coupling of flexural and torsional modes due to fiber orientation of the laminated beams are neglected. Also, the torsional vibrations of the laminated beams analyzed by shear deformation theory in which the shear deformation effects are considered. Numerical analysis has been carried out using finite element method (FEM). The finite element software package ANSYS 10.0 is used to perform the numerical analyses using an eight-node layered shell element to describe the torsional vibration of the laminated beams. Numerical results, obtained by the ANSYS 10.0, classical lamination theory, and shear deformation theory are presented to highlight the effects of fibers orientation and layers stacking sequence on torsional frequencies of the beams.
\end{abstract}

Keywords: Composite materials, Laminated composite beams, Torsional vibrations, Shear deformation, Finite element analysis $* * *$

\section{INTRODUCTION}

The composite beam members have been increasingly used over the past few decades in the fields of aerospace, civil and mechanical engineering due to their excellent engineering features. A variety of structural components made of composite materials such as turbine blades, vehicle axles, aircraft wing, and helicopter blade can be approximated as laminated composite beams, which requires a deeper understanding of the vibration characteristics of the composite beams [1]. Ccomposite beams are generally used as structural components of light-weight heavy load bearing elements because of the high strength-toweight and stiffness-to-weight ratios, the ability of being different strengths in different directions and the nature of being tailored to satisfy the design requirements of strength and stiffness in practical designs. The increased use of laminated composite beams requires a better understanding of vibration characteristics of these beams; it is quite essential in the design of composite beams subjected to dynamic loads. Due to the composite beams widely used in a variety of structures as well as their substantial benefits and great promise for future application, the dynamic behaviors of the laminated composite beams have received widespread attention and have been investigated extensively by many researchers. A number of researchers have been developed numerous solution methods to analysis the dynamic behaviors of the laminated composite beams [2], [3], and [4]. [5] addressed a free vibration analysis of functionally graded beams via hierarchical models, which were derived via a unified formulation. Giunta et al. [6] presented a unified formulation for the free vibration and elastic stability analysis of three-dimensional sandwich beams, in which shear deformation, in- and out-of-plane warping and rotary inertia were accounted for. Giunta et al. [7] investigated the free vibration of simply supported, cross-ply beams via several higher-order displacement- based theories accounting for nonclassical effects. 
Vidal and Polit [8,9] developed a three-noded beam element on the basis of a sinus distribution with layer refinement for the dynamic analysis of laminated beams. Vidal and Polit [10] performed the vibration analysis of laminated beams by use of the Murakami's zig-zag function in the sine model. Vo and Thai $[11,12]$ investigated the free vibration of axially loaded composite beams with arbitrary lay-ups using the parabolical shear dreformation theory. Based on the sinusoidal shear dreformation theory, Vo et al. [13] developed a finite element model to study the vibration and buckling of composite beams with arbitrary lay-ups.

In designing structures, it is critical to know the natural frequencies of the structure. If a natural frequency of the structure is close to an excitation frequency, then severe vibration of the structure could occur. This condition is called resonance and to avoid resonance, the natural frequencies of the structure must be altered by making suitable adjustments in the design. The study of such free vibrations (free because the structure vibrates with no external forces) is very important in finding the dynamic response of the elastic structure. Thus, in the dynamic analyses, it is quite essential to consider an overview of the free vibration characteristics, including the natural frequencies of these composite structures. [14] performed the free vibration analyses of generally laminated composite beams using the method of Lagrange multipliers. Jang and Lee [15] presented a spectral element model for the axialbending-shear coupled vibrations of axially loaded laminated Timoshenko beams.

Free vibration analysis of laminated beams has been conducted by significant amount of research. Yõldõrõm and Kõral [16] studied the out-of-plane free vibration problem of symmetric cross-ply laminated beams using the transfer matrix method. Also, the effects of the rotary inertia and shear deformation are investigated under various boundary conditions. Banerjee, J. [17] investigated the free vibrations of axially loaded composite Timoshenko beams using the dynamic stiffness matrix method by developing an exact dynamic stiffness matrix of composite beams taking into account the effects of an axial force, shear deformation, and rotatory inertia. The theory includes the material coupling between the bending and torsional modes of deformations. Jun et al. [18] investigated the free vibration and buckling behaviors of axially loaded laminated composite beams having arbitrary lay-up using the dynamic stiffness method taking into account the influences of axial forces, Poisson effect, axial deformation, shear deformation, and rotary inertia. They developed the exact dynamic stiffness matrix by directly solving the governing differential equations of an axially loaded laminated beam. Eisenberger, M. et al. [19] used the dynamic stiffness analysis and the first-order shear deformation theory to study the free vibration of laminated beams. Calım, F. [20] make study intended to analyze free and forced vibrations of nonuniform composite beams in the Laplace domain. Khdeir and Reddy [2] have been studied free vibrations of cross-ply laminated beams with arbitrary boundary conditions.
Krishnaswamy, S. et al. [3] gave analytical solutions for the free vibration problem of laminated composite beams. Song and Waas [22] have been studied both buckling and free vibration analyses of laminated composite beams. They Song and Waas [22] also investigated the shear deformation effects. Yildirim, V. [23] used the stiffness method for the solution of the purely inplane free vibration problem of symmetric cross-ply laminated beams with the rotary inertia, axial and transverse shear deformation effects included by the first-order shear deformation theory. Chandrashekhara and Bangera [24] investigated the free vibration of angle-ply composite beams by a higher-order shear deformation theory using the shear flexible FEM. Teh and Huang [25] presented two finite element models based on a firstorder theory for the free vibration analysis of fixed-free beams of general orthotropic. Carrera et al. [26] presented hierarchical beam elements on the basis of a unified formulation, where the displacement components were expanded in terms of the section coordinates. On the basis of a unified formulation, Biscani et al. [27] formulated variable kinematics beam elements, which were combined through the Arlequin method. Giunta et al.

Several researchers have carried out studies on experimental and theoretical evaluations of flexural- torsional vibration analysis for FRP structural members. Lee and Kim [28] studied free vibration of a thin-walled laminated composite beam, where a general analytical model applicable to the dynamic behavior of a thin-walled channel section composite is developed. This model is based on the classical lamination theory, and accounts for the coupling of flexural and torsional modes for arbitrary laminate stacking sequence. Shadmehri, F. et al. [29] studied the flexuraltorsional behavior of thin-walled composite beams with closed cross-section and a number of non-classical effects, such as material anisotropy, transverse shear, are considered in the study. Kollar, LP. [30] investigated the analysis of Flexuraltorsional vibration of open section composite beam with including shear deformation. Qiao et al. [31] presented a combined analytical and experimental approach to characterize the vibration behavior of pultruded Fiber-Reinforced Plastic (FRP) composite cantilever I-beams.

In engineering practice, we often come across the analysis of structures subjected to vibratory twisting loading, such as aerodynamic or asymmetric traffic forces. Also, composite structural elements consisting of a relatively weak matrix reinforced by stronger inclusions or of different materials in contact are of increasing technological importance in engineering. Steel beams or columns totally encased in concrete are most common examples, while construction using steel beams as stiffeners of concrete plates is a quick, familiar and economical method for long bridge decks or for long span slabs.

The extensive use of the aforementioned structural elements necessitates a rigorous dynamic analysis. Several researchers have dealt with torsional vibration of beams. Eisenbeger, M. [32] studied the torsional vibration of open and variable cross section bars by derive analytical method is to form the dynamic stiffness 
matrix of the bar, including the effect of warping. Kameswara and Mirza [33]studied the problem of free torsional vibration and buckling of doubly symmetric thin-walled beams of open section, subjected to an axial compressive static load and resting on continuous elastic foundation. Evangelos and Sapountzakis [34] studied the Torsional vibrations of composite bars by (BEM) boundary element method which is developed for the non-uniform torsional vibration problem of doubly symmetric composite bars of arbitrary constant cross-section.

In the present study, the torsional vibration behavior of symmetrical laminated composite beams are studied. The laminated beam is modeled and analyzed by the FEM. The commercial finite element program ANSYS 10.0 is used to perform a dynamic modelling to the laminated beams by performing an eigenvalue analysis. Mindlin eight-node isoparametric layered shell elements (SHELL 99) are employed in the modeling for describing the torsional vibrations of these beams. Also, analytical models are developed by classical lamination theory and shear deformation theory to study the torsional vibrations of the beams. In the analytical models, the flexural-torsional coupling effects are ignored and pure torsional vibrations are taken. The effects of fiber direction and laminate stacking sequence on the frequencies of torsional vibrations were investigated. Also, the effects of boundary conditions on the torsional frequencies of the laminated beams are demonstrated.

\section{MATERIAL AND GEOMETRY}

A generally laminated composite beam with a solid rectangular cross-section of doubly symmetrical cross sections, as shown in Figure 1, is considered to be studied. The laminated beam is made of many plies of orthotropic materials, and the principal material axes of a ply may be oriented at an arbitrary angle with respect to the $\mathrm{x}$-axis. In the right-handed Cartesian coordinate system, the $\mathrm{x}$-axis is coincident with the beam axis and its origin is on the mid-plane of the beam. The length, breadth and thickness of the beam are represented by $L, b$ and $h$, respectively.

Glass fiber (E-Glass) is used as reinforcement in the form of unidirectional fibers with epoxy resin as matrix for the laminated composite beams. The mechanical properties for fiber and matrix are presented in Table 1 [35]. For all finite element and analytical models, their associate material elastic properties were calculated analytically using the simple rule-of-mixtures as given in [36]. More accurate values can be further obtained with some mechanical testing.

The constituent laminate were considered to be linear elastic and generally orthotropic therefore the concept of engineering constants was used to describe the laminae elastically. A certain set of elastic properties is required as input parameters for the finite element code and for the analytical models. The set of properties required as an input parameter at a material level were
$E_{1}, E_{2}, E_{3}, G_{12}, G_{13}, G_{23}, v_{12}, v_{13}$ and $v_{23}$ as shown in Table 1; Where 1,2 , and 3 are principal material directions.

Table 1 Material elastic properties

\begin{tabular}{|c|c|c|}
\hline Material & Properties & Value \\
\hline \multirow[t]{5}{*}{ Glass fiber } & $\begin{array}{c}\text { Fiber longitudinal modulus in } \ell \\
\text { direction Ef } \ell(\mathrm{GPa})\end{array}$ & 74 \\
\hline & $\begin{array}{c}\text { Fiber transverse modulus in } \mathrm{t} \\
\text { direction Eft }(\mathrm{GPa})\end{array}$ & 74 \\
\hline & Fiber shear modulus Gf $\ell \mathrm{t}(\mathrm{Gpa})$ & 30 \\
\hline & Density $\rho f(\mathrm{~kg} / \mathrm{m} 3)$ & 2600 \\
\hline & Fiber Poisson ratio $\mathrm{vflt}$ & 0.25 \\
\hline \multirow{4}{*}{$\begin{array}{l}\text { Epoxy } \\
\text { resin }\end{array}$} & Elastic modulus E (Gpa) & 4.5 \\
\hline & Shear modulus G (Gpa) & 1.6 \\
\hline & Density $\rho \mathrm{m}(\mathrm{kg} / \mathrm{m} 3)$ & 1200 \\
\hline & Poisson ratio $v$ & 0.4 \\
\hline \multirow[t]{11}{*}{$\begin{array}{l}\text { orthotropic } \\
\text { Laminae }\end{array}$} & $\begin{array}{l}\text { Lamina longitudinal modulus E1 } \\
\qquad(\mathrm{GPa})\end{array}$ & 46.2 \\
\hline & $\begin{array}{c}\text { Lamina transverse modulus E2 } \\
(\mathrm{GPa})\end{array}$ & 14.70 \\
\hline & $\begin{array}{l}\text { Lamina transverse modulus E3 } \\
(\mathrm{GPa})\end{array}$ & 14.70 \\
\hline & Density of composite $\rho c(\mathrm{~kg} / \mathrm{m} 3)$ & 2040 \\
\hline & $\begin{array}{l}\text { Lamina shear modulus in plane } \\
1-2 \mathrm{G} 12(\mathrm{GPa})\end{array}$ & 5.35 \\
\hline & $\begin{array}{l}\text { Lamina shear modulus in plane } \\
1-3 \mathrm{G} 13(\mathrm{GPa})\end{array}$ & 5.35 \\
\hline & $\begin{array}{l}\text { Lamina shear modulus in plane } \\
2-3 \mathrm{G} 23(\mathrm{GPa})\end{array}$ & 5.22 \\
\hline & $\begin{array}{l}\text { Major Poisson ratio in plane } \\
1-2 v 12\end{array}$ & 0.31 \\
\hline & $\begin{array}{l}\text { Major Poisson ratio in plane } \\
1-3 \text { v13 }\end{array}$ & 0.31 \\
\hline & $\begin{array}{l}\text { Major Poisson ratio in plane } \\
2-3 \text { v23 }\end{array}$ & 0.41 \\
\hline & Fiber volume fraction vf & $60 \%$ \\
\hline
\end{tabular}

\section{MODAL ANALYSIS BY FINITE-ELEMENT}

\section{METHOD, ANSYS}

The beams were discretized using (type shell99) finite element as shown in Figure 2, available in the commercial package ANSYS10.0. This element has 8 nodes and is constituted by layers that are designated by numbers (LN - Layer Number), increasing from the bottom to the top of the laminate; the last number quantifies the existent total number of layers in the laminate (NL - Total Number of Layers).The element has six degrees of freedom at each node: translations in the nodal $x, y$, and $\mathrm{z}$ directions and rotations about the nodal $\mathrm{x}, \mathrm{y}$, and $\mathrm{z}$-axes. The choice of shell99 element type is based on layered applications of a structural shell model, and the type of results that need to be calculated. 
$\mathrm{x}_{\mathrm{IJ}}=$ Element $\mathrm{x}$-axis if ESYS is not supplied.

$\mathrm{x}=$ Element $\mathrm{x}$-axis if ESYS is supplied.

A modal analysis will be carried out using ANSYS 10.0 finite element software to study the frequencies of free torsional vibrations of the mentioned composite laminated beam.

\section{DYNAMIC MODELING BY ANALYTICAL METHODS}

In the present paper, the free torsional vibrations of symmetric laminated beams are studied by the classical lamination theory and shear deformation theory.

When the cross-section has one plane of symmetry, one of the circular frequencies belongs to a flexural mode and the other two circular frequencies to flexural-torsional modes; while when the cross-section has two planes of symmetry, the three circular frequencies belong respectively to the flexural modes in the two planes of symmetry and to the pure torsion mode (when the axis of the beam does not bend). The bending-torsion coupling due to stiffness coupling presented in composite beams due to fiber orientation and stacking sequence is neglected.

\subsection{Classical Beam Theory}

The oldest and the well-known beam theory is the EulerBernoulli beam theory (or classical beam theory-CBT), in which the shear deformation not included. Although this theory is useful for slender beams, it does not give accurate solutions for thick beams. The beams to be studied are orthotropic and its cross section has two axes of symmetry y and $\mathrm{z}$. The mass is also symmetrical with respect to these axes, and, accordingly, the center of mass coincides with the origin of the $y-z$ coordinate system, so that the flexural-torsional coupling not occurs.

A beam with two cross-sectional planes of symmetry may undergo flexural vibration in either of the two planes of symmetry and torsional vibration [37]. Pure torsional vibrations are focused in this study.

Expressions for the torsional vibration $\omega \mathrm{B} \psi \mathrm{i}$ of long $\left(\overline{\mathrm{GI}}_{\mathrm{t}} \gg \overline{E I}_{\omega} / L^{2}\right)$ and short $\left(\overline{\mathrm{GI}}_{\mathrm{t}} \ll<\overline{E I}_{\omega} / L^{2}\right)$ orthotropic beams are:

Torsional vibration of long beam is given by:

$$
\left(\omega_{\Psi i}^{B}\right)^{2}=\frac{\overline{G I}_{t}}{2 \pi * \theta} \frac{\mu_{G i}^{2}}{L^{2}}
$$

Torsional vibration of short beam is given by:

$$
\begin{aligned}
& \left(\omega_{\Psi i}^{B}\right)^{2}=\frac{\overline{E I} \omega}{2 \pi * \theta} \frac{\mu_{B i}^{4}}{L^{4}} \\
& \theta=\int_{(A)} \rho_{c o m p}\left(y^{2}+z^{2}\right) d A
\end{aligned}
$$

Where $\overline{\mathrm{GI}}_{\mathrm{t}}$ is the torsional stiffness of the beam; in N.m2,

$\overline{E I}_{\omega}$ is the warping stiffness of the beam; in N.m4, $\theta$ is the polar moment of mass per unit length about the shear center, pcomp is mass per unit volume, $\mathrm{A}$ is the area of the cross section, and $\mu 4 \mathrm{Bi}$ and $\mu 4 \mathrm{Gi}$ are parameters in the calculation of natural frequencies, which are given in Table 2.

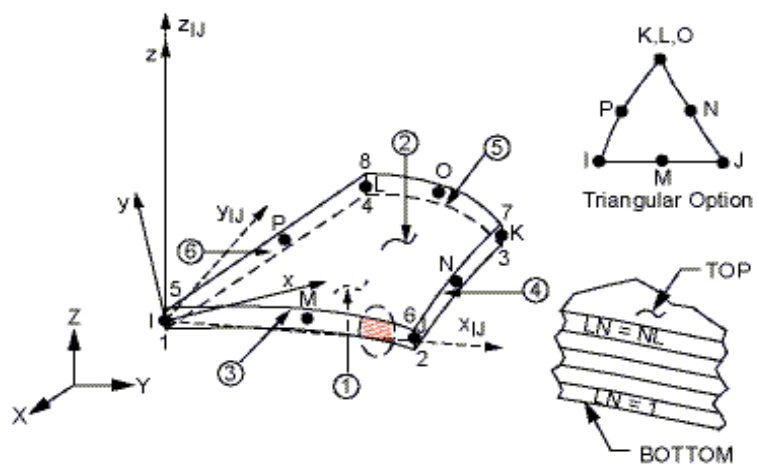

Fig 2 Shell99 geometry

The torsional frequencies of a beam of arbitrary length can be approximated by:

$$
\left(\omega_{\psi i}^{B}\right)^{2}=\left(\omega_{\psi i}^{B}\right)^{2}{ }_{\text {short }}+\left(\omega_{\psi i}^{B}\right)^{2}{ }_{\text {long }}
$$

By using the previous two equations of torsional vibration, the torsional frequencies will be:

$$
\left(\omega_{\psi i}^{B}\right)^{2}=\frac{\overline{E I}_{\omega}}{2 \pi * \theta} \frac{\mu_{B i}^{4}}{L^{4}}+\frac{\overline{G I}_{t}}{2 \pi * \theta} \frac{\mu_{G i}^{2}}{L^{2}}
$$

For symmetric orthotropic laminated beam previously mentioned; the torsional stiffness of the beam $\overline{\mathrm{GI}}_{\mathrm{t}}$ can be obtained by this relation,

$$
\overline{\mathrm{GI}}_{\mathrm{t}}=\frac{4 b}{d_{66}} \text { in (N.m2) }
$$


and Warping stiffness of the beam $\overline{E I}_{\omega}$ can be obtained by this relation,

$$
\overline{E I}_{\omega}=\frac{b^{3}}{a_{11}} \frac{h^{2}}{144} \text { in (N.m4) }
$$

Where:

a11: element $1-1$ of the laminate extensional compliance matrix $(\mathrm{m} / \mathrm{N})$

d66: element $6-6$ of the laminate bending compliance matrix $(1 / \mathrm{N} . \mathrm{m})$

Table 2 The constants $\mu \mathrm{Bi}$ and $\mu \mathrm{Gi}$ for for different types of end supports

\begin{tabular}{|l|l|l|}
\hline Geometry & $\mu \mathrm{B}$ & $\mu \mathrm{G}$ \\
\hline Clamped-Free & $\begin{array}{l}\mu \mathrm{B} 1=1.875 \\
\mu \mathrm{B} 2=4.694 \\
\mu \mathrm{Bi} \approx(\mathrm{i}-0.5)\end{array}$ & $\mu \mathrm{Gi} \approx(\mathrm{i}-0.5) \pi$ \\
\hline Clamped-Clamped & $\begin{array}{l}\mu \mathrm{B} 1=4.730 \\
\mu \mathrm{B} 2=7.853 \\
\mu \mathrm{Bi} \approx(\mathrm{i}+0.5) \pi\end{array}$ & $\mu \mathrm{Gi}=\mathrm{i} \pi$ \\
\hline $\begin{array}{l}\text { Clamped-Simply } \\
\text { supported }\end{array}$ & $\begin{array}{l}\mu \mathrm{B} 1=3.927 \\
\mu \mathrm{B} 2=7.069 \\
\mu \mathrm{Bi} \approx(\mathrm{i}+0.25) \pi\end{array}$ & $\mu \mathrm{Gi}=\mathrm{i} \pi$ \\
\hline $\begin{array}{l}\text { Simply supported- } \\
\text { Simply supported }\end{array}$ & $\mu \mathrm{Bi}=\mathrm{i} \pi$ & $\mu \mathrm{Gi}=\mathrm{i} \pi$ \\
\hline
\end{tabular}

\subsection{Shear Deformation Theory}

The theory, based on the assumption that cross sections remain plane but not perpendicular to the axis is frequently called firstorder shear theory. A beam, in which shear deformation is taken into account, is called a Timoshenko beam. In shear deformation theory the effect of the shear deformation is considered in torsional frequencies calculation as given by [17].

Torsional vibration with shear deformation $\omega \psi \mathrm{i}$ of short $\left(\overline{\mathrm{GI}}_{\mathrm{t}} L^{2}<<\overline{E I}_{\omega}\right)$ and long $\left(\overline{\mathrm{GI}}_{\mathrm{t}} L^{2}\right\rangle \overline{E I}_{\omega}$ and $\left.\bar{S}_{\omega \omega} L^{2} \gg \overline{E I}_{\omega}\right)$ orthotropic beams are:

Torsional vibration of short beam is given by,

$$
\left(\omega_{\psi i}\right)^{2}=\left[\frac{\theta}{\overline{E I}_{\omega}}\left(\frac{L}{\mu_{B i}}\right)^{4}+\frac{\theta}{\bar{S}_{\omega \omega}}\left(\frac{L}{\mu_{S i}}\right)^{2}\right]^{-1}
$$

Torsional vibration of long beam is given by,

$$
\left(\omega_{\Psi_{i}}\right)^{2}=\frac{\overline{G I}_{t}}{\theta} \frac{\mu_{G i}^{2}}{L^{2}}
$$

The torsional circular frequency of a beam of arbitrary length can be approximated by:

$$
\left(\omega_{\psi i}\right)^{2}=\left(\omega_{\psi i}\right)_{\text {short }}+\left(\omega_{\psi i}\right)^{2}{ }_{\text {long }}
$$

By using Eqs. (8) and (9) then,

$$
\left(\omega_{\psi i}\right)^{2}=\left[\frac{\theta}{\overline{E I}_{\omega}}\left(\frac{L}{\mu_{B i}}\right)^{4}+\frac{\theta}{\bar{S}_{\omega \omega}}\left(\frac{L}{\mu_{S i}}\right)^{2}\right]^{-1}+\frac{\overline{G I}_{t}}{\theta} \frac{\mu_{G i}^{2}}{L^{2}}
$$

Where the torsional shear stiffness is given by,

$$
\bar{S}_{\omega \omega}=\frac{b h^{2}}{1.2 a_{66}}
$$

Where a66 is element 6-6 of the laminate extensional compliance matrix $(\mathrm{m} / \mathrm{N})$

\section{NUMERICAL RESULTS AND DISCUSSION}

\subsection{Influence of Fiber Angle on Torsional Natural Frequencies}

The influences of fiber orientation are investigated by modeling laminated beams of different lay-up construction of clamped free boundary condition as shown in Figure 1. The analysis was performed to 8-layered symmetrically laminated beam with length $400 \mathrm{~mm}$, width $40 \mathrm{~mm}$ and thickness $3.2 \mathrm{~mm}$ and the lamination scheme of beams is ranging from $\theta=00$ to 900 , in increments of 50 .

The results obtained after modeling the beams are presented in Figure 3. It presents the variation of the lowest three torsional natural frequencies of the beam with respect to fiber angle. From the results, It is seen that the torsional frequencies increase with increasing the fiber angle of the laminated beams until reach to significant values in the range from about $\theta=350$ to $\theta=450$, then the torsional frequencies decrease gradually with increasing the fiber angle until reach to minimum value at $\theta=900$. 


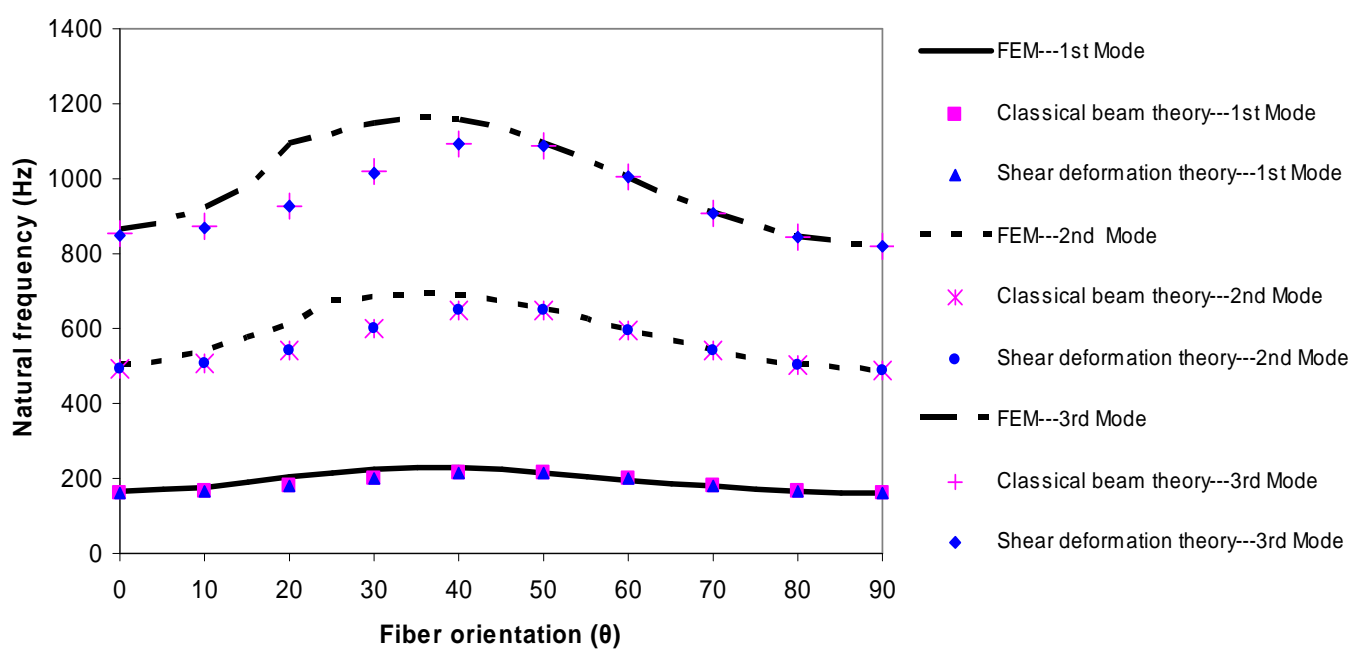

Fig 3. Variation of 1st, 2nd, and 3rd torsional frequencies of Clamped-Free composite beam with respect to fiber angle change

\subsection{Influence Of Laminate Arrangement On Torsional}

\section{Frequencies}

To investigate the influence of laminate stacking sequence, dynamic modeling is performed to 3 set of symmetrical laminates with a total of 8 layers and dimension of $400 \mathrm{~mm}$ length, $40 \mathrm{~mm}$ width and total thickness $3.2 \mathrm{~mm}$. Each layer in the laminate has the same thickness. The lamination schemes of the beams are as follow: (0/90)2S, (45/-45)2S, and (45/ 45/0/90)S. The torsional frequencies are obtained by the analytical methods and by FE package, Table 3. From the table it is noticed that very good agreement between results obtained by FEM, classical beam theory and shear deformation theory. National frequency for laminates with fiber orientation $(+45 /-45)$ is permanent higher than for orientation with (0/90).

Figure 4, give the variation of the torsional natural frequencies of the laminates with respect to mode number for clamped free end condition, from the results it is already possible to verify the influence of the stacking sequence of the laminate on torsional vibration: the laminate with fibers at $+/-450$ has a larger torsional natural frequencies than the laminate of $+/-45 / 0 / 900$ and of $0 / 900$ fibers. This was expected, since the natural frequencies are related to the stiffness of the structure and the $(+/-450)$ is much stiffer on torsion than the $+/-45 / 0 / 900$ and than 0/900 laminate.

The laminate of $0 / 900$ fibers have the lowest torsional natural frequencies than the other lamination schemes and thus, because $50 \%$ of the fibers are oriented at 00 direction for 0/900 laminate, and thus appropriate for bending (Flexural Modes). This can be explained by the fact that the fibers oriented at 00 are more appropriate to flexural loads and the fibers oriented at 450 are more appropriate to torsional loads, i.e. when designer have flexural load it is better to use 0/90 laminates and when applied loads are torsional, laminates with orientation at 450 is more appropriate.

The mode shapes associated with the torsional natural frequencies of (0/90)2S laminated beam are illustrated in Figure 5. They are deduced by FEM ANSYS for the first six torsional frequencies.

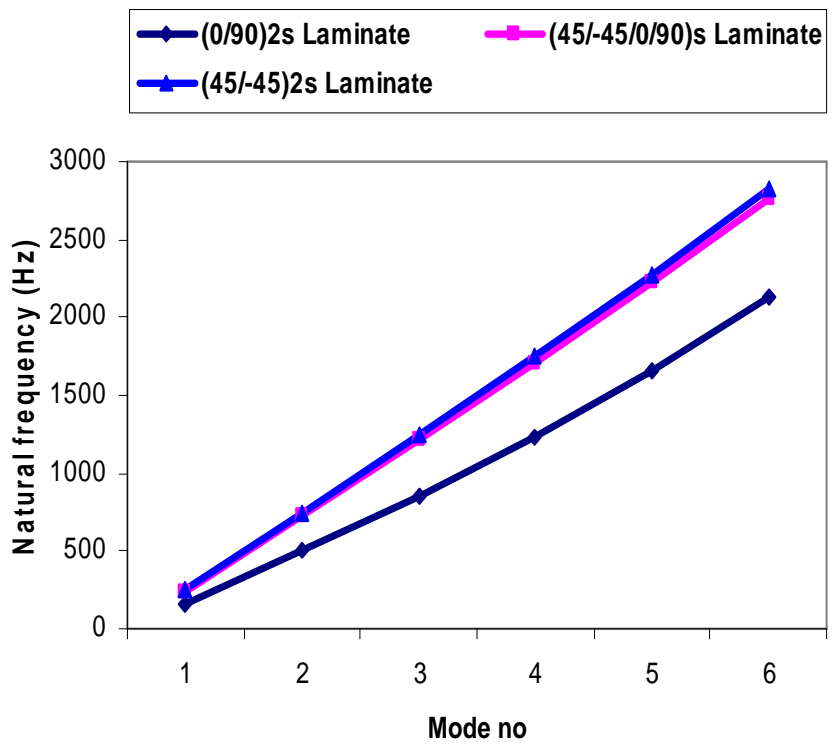

Fig 4. Influence of laminate stacking sequence on torsional natural frequencies for clamped free boundary condition 
Table 3 Torsional natural frequencies $(\mathrm{Hz})$ for different stacking sequences laminate

\begin{tabular}{|c|c|c|c|c|c|c|c|}
\hline \multirow[t]{2}{*}{ Lamination schemes } & \multirow[t]{2}{*}{ Theory } & \multicolumn{6}{|l|}{ Modes } \\
\hline & & 1 & 2 & 3 & 4 & 5 & 6 \\
\hline \multirow{3}{*}{$(0 / 90) 2 \mathrm{~S}$} & FEM ANSYS & 164.24 & 499.13 & 852.68 & 1236.00 & 1657.00 & 2125.00 \\
\hline & Classical Beam Theory & 161.90 & 490.40 & 836.00 & 1208.40 & 1616.30 & 2067.40 \\
\hline & Shear deformation Theory & 161.80 & 490.30 & 835.20 & 1204.00 & 1602.70 & 2033.00 \\
\hline \multirow[t]{3}{*}{$(45 /-45) 2 S$} & FEM ANSYS & 246.40 & 741.30 & 1242.00 & 1754.00 & 2280.00 & 2824.00 \\
\hline & Classical Beam Theory & 250.30 & 752.70 & 1261.20 & 1779.40 & 2311.00 & 2860.00 \\
\hline & Timoshenko & 250.30 & 752.70 & 1261.10 & 1779.00 & 2310.00 & 2856.80 \\
\hline \multirow[t]{3}{*}{$(45 /-45 / 0 / 90) \mathrm{s}$} & FEM ANSYS & 239.00 & 720.00 & 1208.00 & 1709.00 & 2227.00 & 2767.00 \\
\hline & Classical Beam Theory & 242.50 & 730.10 & 1227.00 & 1738.70 & 2270.90 & 2828.70 \\
\hline & Shear deformation Theory & 242.50 & 730.00 & 1226.80 & 1737.60 & 2267.00 & 2819.00 \\
\hline
\end{tabular}

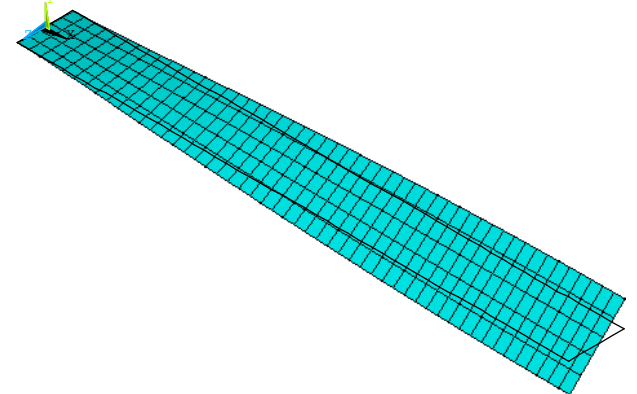

1st Mode - $164.24 \mathrm{~Hz}$

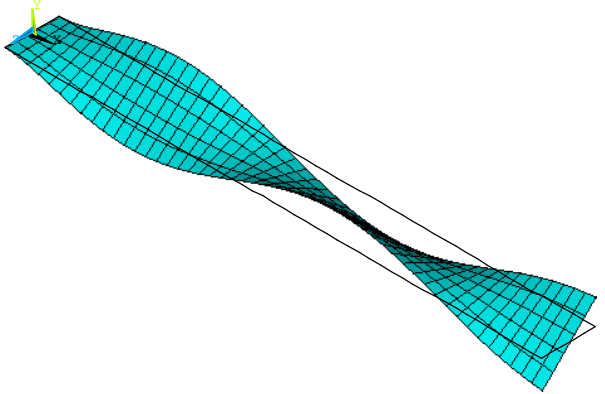

3rd Mode $-852.68 \mathrm{~Hz}$

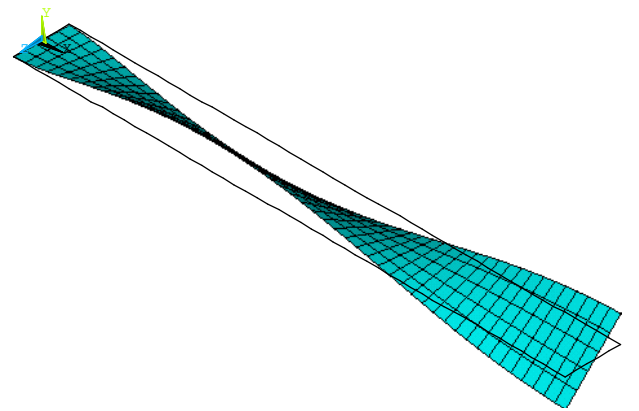

2nd Mode - $499.13 \mathrm{~Hz}$

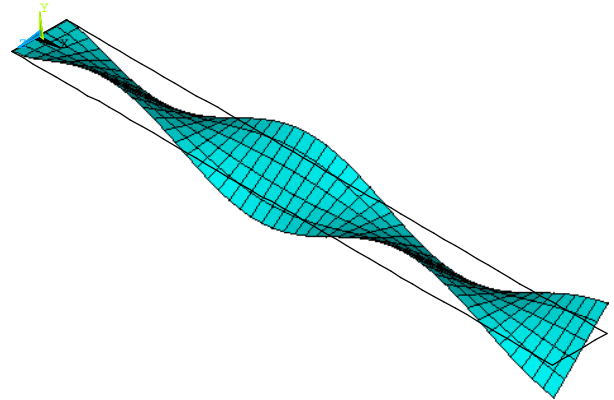

4th Mode - $1236 \mathrm{~Hz}$ 


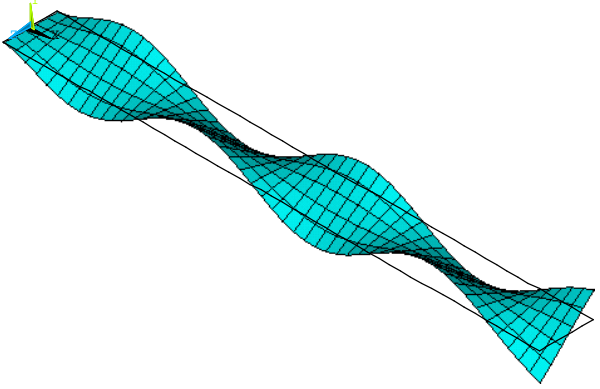

5th Mode $-1657 \mathrm{~Hz}$

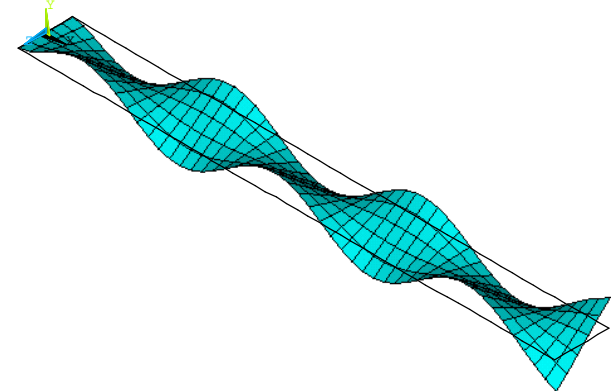

6th Mode $-2125 \mathrm{~Hz}$

Fig 5. The torsional vibration modes of (0/900) clamped-free laminated beam

\subsection{Effect Of Boundary Conditions On Torsional}

\section{Frequencies}

The FE analyses by using ANSYS are used to investigate the influences of boundary conditions on torsional frequencies of the laminated beams. The analysis can be applied to the laminated beam previously mentioned with the same dimensions and geometry. The boundary conditions to be investigated in this study are as follow: C-F Clamped-Free, C-C ClampedClamped, C-S Clamped-Simply-Supported, and S-S Simply Supported - Simply Supported.

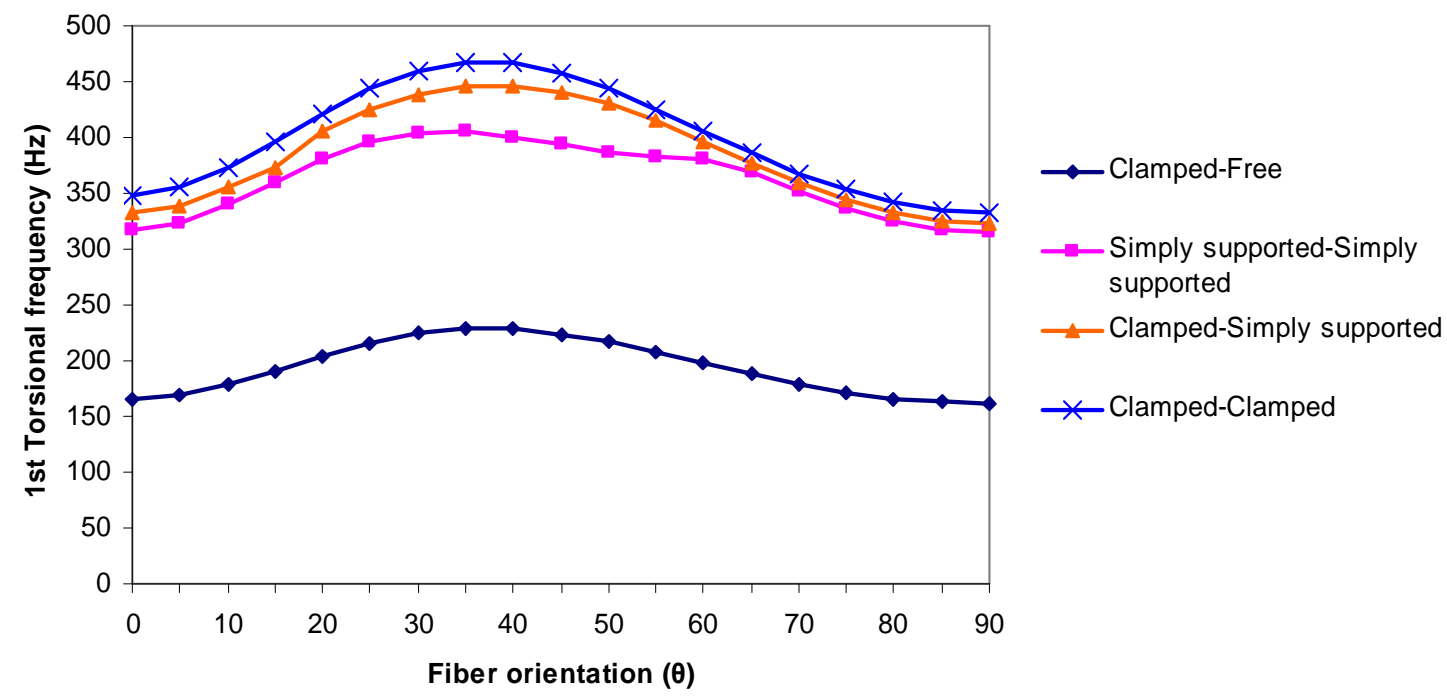

Fig 6. Influence of boundary conditions on 1st torsional natural frequency frequency

The influence of boundary conditions on torsional natural frequencies is investigated for the 1 st torsional frequency as shown in Figure 6. From the results, It is seen that the clamped-clamped condition has a larger torsional frequency than other boundary fixations, and thus for all fiber angles. The torsional frequency for clamped-simply supported condition comes to be lower than clamped-clamped condition, then simply supported-simply supported comes to be lower than clamped-simply supported, and finally clamped-free condition comes to be lower than other supports.

\section{CONCLUSIONS}

In the present study, the torsional vibrations behaviors of symmetrical laminated composite beams are studied. 
The laminated beams is modeled and analyzed by the FEM. The commercial finite element program ANSYS 10.0 is used to perform a dynamic modeling to the laminated beams by performing an eigenvalue analysis, Aanalytical models are conducted by classical lamination theory and shear deformation theory to study the torsional vibrations of the beams. The following conclusions could be cited:

1) Through the results, it is demonstrated that results by FEM ANSYS have shown to be in a good agreement with the analytical solutions, the results by classical lamination theory and shear deformation theory.

2) From the results, it is clear that changes in fiber angle as well as laminate stacking sequences yield to different dynamic behavior of the component, that is, different torsional natural frequencies for the same geometry, mass and boundary conditions.

3) It is seen that the torsional frequencies increase with increasing the fiber angle of the laminated beams until reach to significant value at about $\theta=45^{\circ}$, then the torsional frequencies decrease gradually with increasing the fiber angle until reach to minimum value at $\theta=90^{\circ}$.

4) This result is very attractive since it makes abilitye to obtain the desired torsional natural frequencies without increasing mass or changing geometry. In practical applications, it means that if a torsional natural frequency excites the structure, the designer can change the material properties by changing the laminate stacking sequence, instead of re-design the complete structure.

5) The finite element software package ANSYS is an efficient vibration prediction tool, because of its ability to model the laminated composite beam and reveal fundamental modal frequencies and modal shapes.

6) Finally this study is useful for the designer in order to select the fiber orientation angle to shift the torsional natural frequencies as desired or to control the vibration level.

\section{REFERENCES}

[1] Kapuria S, Alam N., "Efficient layerwise finite element model for dynamic analysis of laminated piezoelectric beams", Computer Methods in Applied Mechanics and engineering", Vol. 195, Issues 19-22, pp. 2742-2760, 2006.

[2] Khdeir A.A., Reddy J.N. "Free vibration of cross-ply laminated beams with arbitrary boundary conditions", International Journal of Engineering Science, Vol. 32, Issue 12, pp.1971-1980, 1994.

[3] Krishnaswamy S., Chandrashekhara K., Wu W.Z.B. "Analytical solutions to vibration of generally layered composite beams"., Journal of Sound and Vibration, Vol. 159, Issue 1, pp. 85-99, 1992.

[4] Matsunaga H. "Vibration and buckling of multilayered composite beams according to higher order deformation theories", Journal of Sound and Vibration, Vol. 246, Issue 1, pp.47-62, 2001.
[5] Giunta G, Crisafulli D, Belouettar S, Carrera E."Hierarchical theories for the free vibration analysis of functionally graded beams" Compos Struct, Vol. 94, pp.68-74, 2011.

[6] Giunta G, Metla N, Koutsawa Y, Belouettar S. "Free vibration and stability analysis of three-dimensional sandwich beams via hierarchical models". Composites, Vol. 47-Part B;:pp. 326-338, 2013.

[7] Giunta G, Biscani F, Belouettar S, Ferreira AJM, Carrera E. Free vibration analysis of composite beams via refined theories. Composites:Vol.44, Part B, pp.540-552, 2013.

[8] Vidal P, Polit O. A family of sinus finite elements for the analysis of rectangular laminated beams. Compos Struct Vol. 84: pp. 56-72, 2008.

[9] Vidal P, Polit O. Vibration of multilayered beams using sinus finite elements with transverse normal stress. Compos Struct, Vol.92: pp.1524-1534, 2010.

[10] Vidal P, Polit O. A sine finite element using a zig-zag function for the analysis of laminated composite beams. Composites: Vol. 42, Part B, pp. 1671-1682, 2011.

[11] Vo TP, Thai HT. "Free vibration of axially loaded rectangular composite beams using refined shear deformation theory" Compos Struct. Vol. 94: pp. 33793387, 2012.

[12] Vo TP, Thai HT. "Vibration and buckling of composite beams using refined shear deformation theory" Int $\mathbf{J}$ Mech Sci. Vol. 62: pp. 67-76, 2012.

[13] Vo TP, Thai HT, Inam F. "Axial-flexural coupled vibration and buckling of composite beams using sinusoidal shear deformation theory" Arch Appl Mech, Vol 83, pp. 605-622, 2013.

[14] Jafari-Talookolaei RA, Abedi M, Kargarnovin MH, Ahmadian MT. "An analytical approach for the free vibration analysis of generally laminated composite beams with shear effect and rotary inertia" Int J Mech Sci,Vol. 65, pp. 97-104, 2012.

[15] Jang I, Lee U. "Spectral element analysis of the axialbending-shear coupled vibrations of composite Timoshenko beams" J Compos Mater, Vol. 46, pp. 2811-2828, 2013.

[16] Yõldõrõm V, Kõral E. "Investigation of the rotary inertia and shear deformation effects on the out-ofplane bending and torsional natural frequencies of laminated beams", Composite Structures, Vol.49, Issue 3, pp. 313-320, 2000.

[17] Banerjee, J.R., (1998), "Free vibration of axially loaded composite timoshenko beams using the dynamic stiffness matrix method", Computers and Structures, Vol. 69,Issue 2, pp. 197-208.

[18] Jun L, Hongxing H, Rongying S. "Dynamic stiffness analysis for free vibrations of axially loaded laminated composite beams" Composite Structures, Vol. 84, Issue 1, pp. 87-98, 2008. 
[19] Eisenberger M, Abramovich H, Shulepov O. "Dynamic stiffness analysis of laminated beams using a first-order shear deformation theory", Composite Structure, Vol. 31, Issue 4, pp. 265-271, 1995.

[20] Calım FF "Free and forced vibrations of non-uniform composite beams", Composite Structures, Volume 88, Issue 3, pp. 413-423, 2009.

[21] Song SJ, Waas A. "Effects of shear deformation on buckling and free vibration of laminated composite beams", Composite Structures, Vol.37, Issue 1, pp.3343, 1997.

[22] Yildirim V. "Effect of the longitudinal to transverse moduli ratio on the in-plane natural frequencies of symmetric cross-ply laminated beams by the stiffness method" Composite Structures, Vol.50, Issue 3, pp. 319-326, 2000.

[23] Chandrashekhara K., Bangera K.M."Free vibration of composite beams using a refined shear flexible beam element", Computer and Structures, Vol. 43, Issue 4, pp. 719-727, 1992.

[24] Teh KK, Huang CC. "The vibration of generally orthotropic beams a finite element approach", Journal of Sound and Vibration, Vol.62, Issue 2, pp.195-206, 1979.

[25] Carrera E, Giunta G, Nali P, Petrolo M. "Refined beam elements with arbitrary cross-section geometries" Comput Struct, Vol. 88, pp. 283-293, 2010.

[26] Biscani F, Giunta G, Belouettar S, Carrera E, Hu H. "Variable kinematic beam elements coupled via Arlequin method. Compos Struct Vol. 93, pp.697-708, 2011.

[27] Lee J., Kim S.E., (2002), "Free vibration of thin-walled composite beams with I-shaped cross-section", Composite Structures,Vol.80, Issue 2, pp. 205-215, 2002.

[28] Shadmehri F., Haddadpour H., Kouchakzadeh, M.A. "Flexural-torsional behavior of thin-walled composite beams with closed cross-section composite beams with channel sections", Thin-Walled Structures, Vol. 45, Issues 7-8, pp. 699-705, 2007.

[29] Kollar LP. "Flexural-torsional vibration of open section composite beam with shear deformation", International Journal of Solids and Structures, Vol. 38, Issues 42-43, pp. 7543-7558, 2001.

[30] Qiao P., Zou G., Song G., (2002) "Analytical and experimental study of vibration behavior of FRP composite I-beams", 15th ASCE Engineering Mechanics Conference, New York.

[31] Eisenbeger M. " Torsional vibrations of open and variable cross section bars", Thin-Walled Structures, Vol. 28m, Issues 3-4, pp. 269-278, 1997.

[32] Kameswara Rao C., Mirza S., "Torsional vibrations and buckling of thin-walled beams on elastic foundation", Thin-Walled Structures, Vol.7, Issue 1, pp.73-82, 1989.
[33] Evangelos J.,Sapountzakis " Torsional vibrations of composite bars by BEM", Composite Structures, Vol.70, Issue 2, pp.229-239, 2005.

[34] Danial Gay, Hoa SV., Tsai SW., (2003), Composite materials design and applications, Boca Raton, London New York, Washington.

[35] Vinson JR, Sierakowski RL., (2004), The behaviour of structures composed of composite materials, New York, Boston, Dordrecht, Moscow.

[36] La'szlo' P., George S., (2003), Mechanics of composite structures, Cambridge University, New York, United States of America. 